\title{
A lacZ Reporter Transgenic Mouse Line Revealing the Development of Pulmonary Artery
}

\author{
Reina Ishizaki, Keiko Uchida, Akimichi Shibata, \\ Takatoshi Tsuchihashi, Jun Maeda, Katsuhiko Mikoshiba, \\ and Hiroyuki Yamagishi
}

\author{
Keywords \\ Vasculogenesis · Angiogenesis · Cardiovascular system · Pulmonary arterial \\ smooth muscle cell
}

Pulmonary vasculature in mice develops through two main mechanisms, namely angiogenesis and vasculogenesis. At embryonic day (E) 9.5, vascular endothelial marker Tie2-driven LacZ expression in whole-mount transgenic lungs showed continuity between the primitive lung vasculature and the aortic sac [1]. Scanning electron microscopic study of vascular casts and graphic reconstruction in the 32- and 34-somite (E10) embryos demonstrated that the primordium of the pulmonary artery (PA) arose from the proximal portion of the sixth pharyngeal arch artery and ran straight in the caudal direction [2]. At E10.5, though the afferent vessels were not yet defined as vascular tubes, they resembled two plexiform networks that coalesce alongside the trachea. From these observations, "distal angiogenesis" was proposed as a model for the pulmonary vascular morphogenesis where PAs arise from the pharyngeal arch artery and elongate into the lung buds [1]. Another study provided evidence to support vasculogenesis as the mechanism of both proximal and distal vessel formation during the development of murine lungs [3]. Detailed

\footnotetext{
R. Ishizaki $\cdot$ K. Uchida $\cdot$ A. Shibata $\cdot$ T. Tsuchihashi $\cdot$ J. Maeda

Department of Pediatrics, Keio University School of Medicine, Shinjuku, Tokyo, Japan

K. Mikoshiba

SIAIS (Shanghai Institute for Advanced Immunochemical Studies), ShanghaiTech University, Shanghai, China

H. Yamagishi $(\triangle)$

Division of Pediatric Cardiology, Department of Pediatrics,

Keio University School of Medicine, Tokyo, Japan

e-mail: hyamag@keio.jp

(C) The Editor(s) (if applicable) and The Author(s) 2020

T. Nakanishi et al. (eds.), Molecular Mechanism of Congenital Heart Disease

and Pulmonary Hypertension, https://doi.org/10.1007/978-981-15-1185-1_9
} 
analysis using Mercox vascular casts revealed that vasculogenesis occurred peripherally in the lungs to form isolated blood islands and that angiogenesis centrally forms the axial and lateral arteries and veins. The fusion and coalescence of these central and peripheral systems lead to the development of the pulmonary circuit [4]. The earliest connection between the peripheral and central spaces was identified between E13 and E14.

Muscularization is part of the gradual maturation process of airways and vessels in the lungs [1]. Cells positive for $\alpha$-smooth muscle actin in the vascular wall of PA are evident at E11.5 $[1,5]$. In terms of local development of vascular smooth muscle, the PA wall is constructed radially, from the inside out, by two separate, but coordinated processes: one is the sequential induction and recruitment of successive cell layers from surrounding mesenchymal progenitor cells and the other is the controlled invasion of the surrounding layer by inner layer cells. Later on in the process, inner layer cells initially divide and migrate extensively within the layer before radially reorienting to either migrate into the second layer or radially divide to send daughter cells into the next developing layer [6].

Through the recent analysis of a transgenic mouse line harboring the lacZ reporter gene in a certain targeted locus, we found that the lacZ marker was specifically expressed in PA smooth muscle cells using whole-mount staining during the lung development (Fig. 9.1). Our results suggest that PA smooth muscle may elongate gradually from the proximal pulmonary trunk to the peripheral pulmonary arteries similar to the "distal angiogenesis" model during development [7].

Fig. 9.1 Visualization of pulmonary artery using a reporter transgenic mouse. Whole-mount $\beta$-galactosidase staining heart and lungs at embryonic day (E) 15.5. The $\beta$-galactosidasepositive pulmonary arteries continuously elongate from the central pulmonary trunk to peripheral small arteries (arrows). Scale bar, $1 \mathrm{~mm}$

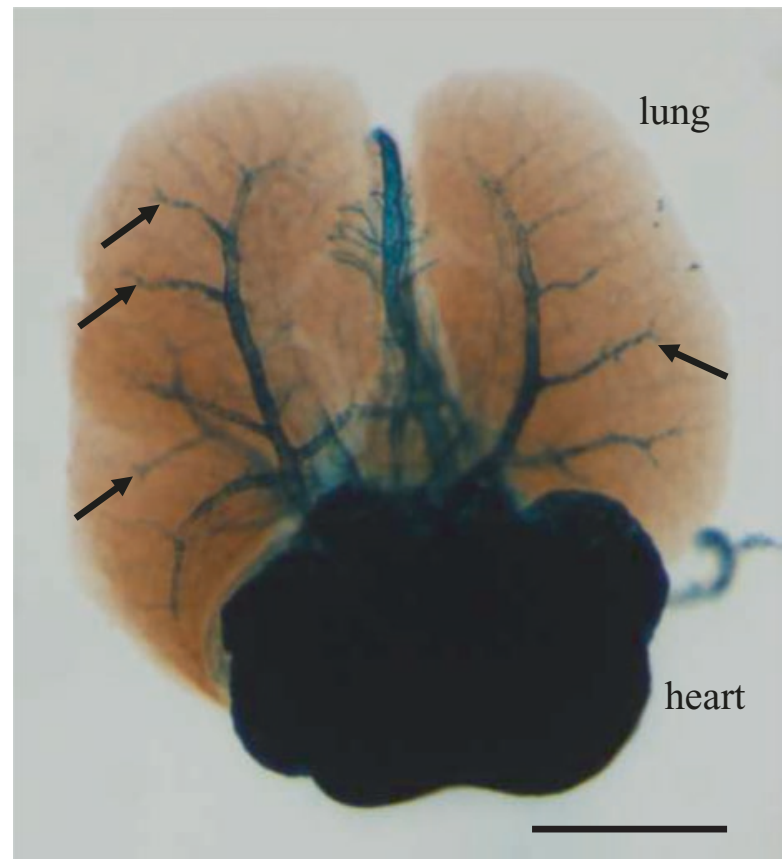




\section{References}

1. Parera MC, van Dooren M. Distal angiogenesis: a new concept for lung vascular morphogenesis. Am J Physiol Lung Cell Mol Physiol. 2005;288(1):L141-9.

2. Hiruma T, Nakajima Y, Nakamura H. Development of pharyngeal arch arteries in early mouse embryo. J Anat. 2002;201(1):15-29.

3. Schachtner SK, Wang Y, Baldwin HS. Qualitative and quantitative analysis of embryonic pulmonary vessel formation. Am J Respir Cell Mol Biol. 2000;22(2):157-65.

4. deMello DE, Sawyer D, Galvin N, et al. Early fetal development of lung vasculature. Am J Respir Cell Mol Biol. 1997;16(5):568-81.

5. Tollet J, Everett AW, Sparrow MP. Spatial and temporal distribution of nerves, ganglia, and smooth muscle during the early pseudoglandular stage of fetal mouse lung development. Dev Dyn. 2001;221(1):48-60.

6. Greif DM, Kumar M, Lighthouse JK, et al. Radial construction of an arterial wall. Dev Cell. 2012;23(3):482-93. https://doi.org/10.1016/j.devcel.2012.07.009.

7. Ishizaki-Asami R, Uchida $\mathrm{K}$, Tsuchihashi $\mathrm{T}$, et al. Inositol 1,4,5-trisphosphate receptor 2 as a novel marker of vasculature to delineate processes of cardiopulmonary development. Dev Biol. 2020;458(2):237-45. https://doi.org/10.1016/j.ydbio.2019.11.011

Open Access This chapter is licensed under the terms of the Creative Commons Attribution 4.0 International License (http://creativecommons.org/licenses/by/4.0/), which permits use, sharing, adaptation, distribution and reproduction in any medium or format, as long as you give appropriate credit to the original author(s) and the source, provide a link to the Creative Commons license and indicate if changes were made.

The images or other third party material in this chapter are included in the chapter's Creative Commons license, unless indicated otherwise in a credit line to the material. If material is not included in the chapter's Creative Commons license and your intended use is not permitted by statutory regulation or exceeds the permitted use, you will need to obtain permission directly from the copyright holder.

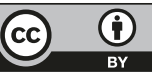

